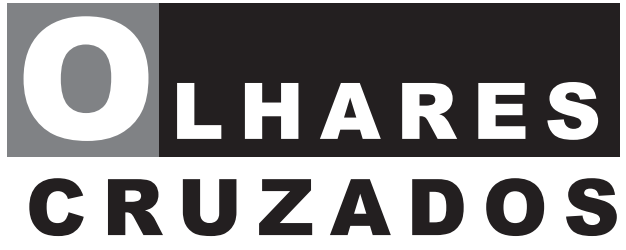




\section{Contexto e normatividade: a formação antropológica no Brasil e no exterior}

\section{Context and normativity: anthropological training in Brazil and abroad}

\section{Leonardo Schiocchet}

Leonardo Schiocchet é doutor em antropologia (Boston University, 2011), pesquisador do Instituto para Antropologia Social da Academia Austríaca de Ciências em Viena, Áustria, e membro fundador da Refugee Outreach and Research Network (ROR-n). Seu trabalho tem enfocado a antropologia do Oriente Médio, com atenção especial para processos de pertencimento social e identidade entre refugiados árabes, sobretudo palestinos, sírios e iraquianos, no Oriente Médio, América Latina e Europa.E-mail: leonardo.schiocchet@oeaw.ac.at

\section{Resumo}

Com base no meu próprio projeto de pesquisa mais amplo entre árabes, sobretudo refugiados (palestinos, sírios e iraquianos), no Líbano (2005-2010), Brasil (20112013), Dinamarca (2013-2015), Palestina e Áustria (2015-2019), este breve ensaio exploratório na forma de testemunho compara a pesquisa acadêmica e em especial o fazer antropológico, no Brasil e fora dele. Meu eixo principal de análise aqui é a relação entre contexto e normatividade acadêmica, que serve de base para discussões sobre o campo institucional da pesquisa antropológica no Brasil em perspectiva comparada e da normatividade do campo acadêmico em escala global. Além disso, contribui a informar e/ou preparar acadêmicos brasileiros para estágios de pesquisa no exterior, oferecendo conhecimento de base para ajustar currículos e expectativas para outros contextos para além do brasileiro.

Palavras-chave: Antropologia, Normatividade, Contexto Acadêmico, Brasil, Exterior, Campo Institucional Acadêmico.

\section{Abstract}

Based on my own wider research project among Arabs (Palestinians, Syrians, and Iraqis) - especially refugees - in Lebanon (2015-2010), Brazil (2011213), Denmark (2013-2015), Palestine and Austria (2015-2019), this brief testimonial essay compares academic research and "doing anthropology" in 
Brazil and elsewhere. My main axis of analysis is the relationship between context and academic normativity, which in turn anchors discussions centered on the institutional field of anthropological research in Brazil and on the global normativity of academia. In addition, this essay contributes to inform and prepare Brazilian academicians for research periods outside of Brazil, bringing knowledge necessary to tailor curricula and expectations to other academic contexts.

Keywords: Anthropology, Normativity, Academic Context, Brazil, Academic Institutional Field.

Com base no meu próprio projeto de pesquisa mais amplo entre árabes, sobretudo refugiados (palestinos, sírios e iraquianos), no Líbano (2005-2010), Brasil (2011-2013), Dinamarca (2013-2015), Palestina e Áustria (2015-2019), este breve ensaio exploratório na forma de testemunho compara a pesquisa acadêmica e em especial o fazer antropológico, no Brasil e fora dele. Meu eixo principal de análise aqui é a relação entre contexto e normatividade acadêmica.

Entendo que minha trajetória acadêmica, tal como apresentada neste ensaio, certamente não pode ser generalizada. Entretanto, sugiro que evidencia questões estruturais importantes sobre o fazer acadêmico/antropológico dentro e fora do Brasil e sobre algumas das potenciais vantagens e desafios da formação, especialmente parcial, de brasileiros fora do Brasil.

Assim sendo, este é estruturado da seguinte forma: em "Situações de pesquisa em contexto", farei uma breve exposição da minha pesquisa nos últimos 14 anos. Depois, em "Pesquisa, perspectiva e o contexto institucional" mostrarei como o desenvolvimento da pesquisa apresentada esteve atrelada ao contexto institucional, social, político e histórico de sua produção. Finalmente, em "Contexto e Normatividade no Fazer Acadêmico" buscarei apontar como minha formação parcial no exterior tem influenciado minha relação com a academia brasileira e discutir a relação entre contexto e normatividade acadêmica, disciplinar e institucional.

Este artigo tem como base duas palestras que proferi sete anos atrás, em 2012. A primeira delas foi para o evento de graduação da primeira turma de especialização em antropologia da Pontifícia Universidade Católica do Paraná 
(PUC-PR); a segunda, foi junto a Gisele Fonseca Chagas, em julho de 2012, na Universidade Federal Fluminense (UFF), como parte do ciclo de palestras "Artes do Fazer", então coordenado por Ana Paula Mendes de Miranda. O que segue, portanto, reflete a análise de um antropólogo brasileiro formado em parte no Brasil (graduação, e um pós-doutorado) e em parte fora dele (doutorado e outros pós-doutorados). Como não poderia deixar de ser, esta perspectiva possui tanto limitações quanto vantagens, possivelmente diferindo significativamente de análises produzidas desde dentro do Brasil. Isso se dá mesmo que eu nunca tenha cortado relações com a antropologia no Brasil - relações que, desde fora, tomam forma diferenciada, já que meus principais interlocutores se encontram em várias partes do mundo, incluindo uma minoria de pesquisadores brasileiros, como descrevo no que segue. Isso, por sua vez, possui fortes implicações para meu próprio fazer antropológico, como sugiro ao longo deste artigo.

\section{SITUAÇÕES DE PESQUISA EM CONTEXTO'}

Entre 2005 e 2018, meu programa de pesquisa mais amplo enfocou o nexo entre o espaço subjuntivo da palestinidade e a diversidade de expressões objetivas que variam de acordo com sujeito e contexto. Esse espaço subjuntivo, isto é, compartilhado e idealizado, real e desejado, deve ser visto como uma arena pública de negociação de pertencimento e organização social, valores e práticas, mas também de disposições, técnicas, afetos e sensitividades incorporadas - todas essas expressões mobilizadas através de complexas motivações não reduzíveis à razão prática ou estratégias conscientes, tampouco completamente inconscientes e estáticas (SCHIOCCHET, 2013, 2015.

Já em 2010, apenas 37,5\% dos palestinos residia nos Territórios Palestinos (Palestinian Bureau of Statistics, 2015). A dispersão da maioria dos palestinos,

Grande parte do material desta seção é um sumário do texto que compõe um capítulo que escrevi para um livro (ainda sem nome) sobre o conceito de diáspora, organizado por Denise Fagundes Jardim e Joseph Handerson, previsto para ser publicado em 2019. Além disso, a parte final desta seção é adaptada de Schiocchet (in press 2019). 
que partiram de um mesmo território chamado então de Palestina, sob o mandato britânico, foi causada pela violência engendrada pelo projeto de colonização sionista e a independência de Israel, e tomou a forma de refúgio e exílio. A despeito dessa dispersão, existe hoje um forte sentimento de pertencimento social palestino e vínculo comunitário, reforçado por uma forte imagética da Palestina originária, e a possibilidade de retorno coletivo se constitui como uma utopia perseguida atrás da ideia de "causa palestina", que marca o local como um destino moral, quando não empírico. Depois de 1948, foi inicialmente desde a Jordânia, depois Líbano, e depois Tunísia que o nacionalismo palestino, mas também a nação palestina, foi significativamente repensada, de forma que o exílio em si se tornou um ponto crucial da própria ideia de palestinidade, negociada transnacionalmente em referência à terra perdida.

Entre a Palestina pré-1948 e o que restou dela, e entre o Oriente Próximo, a Europa e a América Latina, o espaço contextual de negociação de palestinidade é bastante amplo e a experiência da palestinidade na prática varia fortemente. $\mathrm{O}$ pertencimento social de um palestino não se resume à palestinidade, da mesma forma que esta não é engendrada apenas por palestinos. Parte do meu trabalho tem sido entender como, por exemplo, simpatizantes da esquerda política entendem a ideia de "causa palestina" como universal, secular e socialista, imputando esse sentido na própria ideia de palestinidade.

Ser palestino na Cisjordânia não é o mesmo que ser palestino em campos de refugiados no Líbano, em uma pequena cidade da Dinamarca, em Viena, ou quando reassentado desde o Iraque ao Brasil. Meu trabalho de campo com palestinos em todos esses lugares revelou dimensões únicas contextuais e subjetivas, mas também revelou importantes tendências do processo de pertencimento social formando essa arena subjuntiva da palestinidade.

A grande maioria dos refugiados palestinos, que há mais de 65 anos não podem retornar às suas vilas de origem, hoje localizadas em território israelense, vive no Oriente Próximo. Em 2010, cerca de 94\% dos palestinos vivia nos arredores daquilo que a maioria deles define como a Palestina, sem poder retornar a ela. Apenas cerca de 50\% deles vivem hoje no que era a Palestina mandatária, mas pouco menos da metade destes como refugiados. 
O Líbano abriga hoje o que é considerado há muitos anos a população palestina mais vulnerável do mundo, cerca da metade da qual ainda reside dentro de campos de refugiados, constituindo uma das mais antigas situações de refúgio prolongado no mundo. Essa população de refugiados palestinos no Líbano não apenas não possui cidadania em geral, como também não tem assegurados direitos humanos básicos. Como quase todos os palestinos refugiados no Líbano são stateless, o conceito legal de reciprocidade empregado pela lei libanesa os discrimina mesmo em relação a outros estrangeiros. Eles apenas podem sair do país com autorização libanesa, difícil de ser obtida e arriscada, pois não são poucos os casos de sujeitos que viajaram para fora do país com ela e tiveram sua entrada de volta proibida pelas autoridades libanesas.

Mesmo assim, muitos dos palestinos registrados em Al-Jalil, um dos campos de refugiados onde residi durante minha pesquisa de campo no Líbano, conseguiram imigrar já na década de 1980 para a Escandinávia. Os provenientes desse campo em especial se deslocaram sobretudo para a pequena cidade de Arus, na Dinamarca, onde também realizei pesquisa de campo. Em verdade, Al-Jalil é conhecido por outros palestinos no Líbano como "o campo dinamarquês", dado que virtualmente toda a família de refugiados registrados naquele campo possui hoje pelo menos um membro residindo na Dinamarca. Ao contrário do que muitos imaginam, e mesmo do que o próprio governo dinamarquês imaginava com sua política migratória, a maioria desses palestinos não se julga feliz e adaptada ao país escandinavo. Muitos deles obtiveram nacionalidade dinamarquesa no passado, algo quase não obtenível já há muitos anos. Mas mesmo com cidadania, a maioria deles reside em Gellerupparken - um gueto de Arus - junto a curdos, somalis, iraquianos e outros muçulmanos. Durante meu campo, islã era parte do vernacular local de pertencimento social, sobretudo entre jovens, muito mais do que em outros contextos mais marcados por temas nacionais palestinos. Um grande galpão na frente do conjunto residencial Gellerupparken, chamado Bazar Vest, supria a demanda da comunidade por produtos, trabalho e vida comunitária, enquanto duas mesquitas serviam como centros espirituais. Em Arus, não apenas os palestinos compartilhavam o gueto com outras minorias muçulmanas, mas também os dinamarqueses 
tendiam a estigmatizar os muçulmanos, menosprezando categorias de pertencimento nacionais e étnicas. Ao fazê-lo e, concomitantemente, homogeneizar muçulmanos como um grupo coerente, o contexto dinamarquês acabou por impor o islã como principal categoria de identificação para palestinos e outras minorias na Dinamarca. Assim, os centros locais de sociabilidade se tornaram mais associados a atividades religiosas e econômicas do que com folclore e nacionalidade, favorecendo a identificação de imigrantes de segunda geração como movimentos neofundamentalistas transnacionais muçulmanos às custas de movimentos nacionais.

Como movimentos neofundamentalistas islâmicos aqui me refiro ao conceito de Olivier Roy (2004), que por sua vez se refere a grupos relativamente recentes (tais como a Al-Qaeda e o Dảesh²) que buscam a purificação do islã via o expurgo da política, considerada suja. Incidentalmente, essa descrição é bastante semelhante à de Bruno Latour (1993) sobre o processo de purificação advindo da tentativa de secularização do mundo característico do projeto utópico da modernidade. Em verdade, creio que o que Roy descreve e chama de secularização pela religião é mais um impulso que ecoa o encontro do islã com o projeto da modernidade europeia.

Esse processo de islamização dos palestinos na Dinamarca não ocorreu com as mesmas proporções na Áustria, onde palestinos chegaram sobretudo nos anos 1970 como estudantes, não como refugiados, estabelecendo-se como profissionais liberais, tais como médicos, dentistas e advogados e engajando a sociedade civil através da esquerda política em termos não somente políticos, mas também culturais e sociais. Historicamente, essa relação tinha começado já nos tempos do chanceler Bruno Kreisky (década de 1970), que fora do mundo árabe foi diretamente responsável pela legitimação da OLP (Organização para a Libertação da Palestina) como o único representante dos palestinos e abriu caminho para a formulação da causa palestina como universal, secular e socialista para a esquerda política europeia. Entretanto, o grande número de refugiados afegãos e sírios (e entre os sírios, cerca de 800 palestinos), em 2015, rapidamente passou a modificar o contexto austríaco de forma ainda não

\footnotetext{
2 Mais conhecido no Brasil como ISIS.
} 
precisamente clara. Através do que posso inferir até o momento, a influência de ativistas austríacos e da geração de palestinos (e outros árabes) já estabelecida no país continua a reforçar a palestinidade de forma desinteressada em religião - influência esta considerável sobre os refugiados, mas sobretudo entre aqueles politicamente engajados que, em todo caso, não são os motivados a se mobilizar na direção do que Roy (2002) chama de movimentos neofundamentalistas islâmicos.

No Brasil, neofundamentalismo e ortodoxia religiosa também não atraiu um grupo de, inicialmente, 114 palestinos refugiados reassentados desde o Iraque ao Brasil em 2007, e tampouco as gerações mais antigas de palestinos e outros árabes chegados ao Brasil a partir da primeira metade do século XX. Entretanto, o pan-arabismo seduziu mais do que em outros lugares. Quase todos os palestinos refugiados do grupo (SCHIOCCHET, 2019) reassentado no Brasil veio do campo de refugiados Rwayshed, na Jordânia, para onde eles haviam sido enviados por terem sido perseguidos após a queda de Saddam Hussein em 2003. Quase todos esses refugiados eram muçulmanos, com exceção de uma só família. Além disso, quase todos eles, incluindo a família cristã, elogiava Hussein como uma grande líder popular secular, sendo que muitos deles tinham sido empregados na máquina administrativa iraquiana governada pelo Bảath. Essa conexão se deu especialmente porque Hussein rotulou a causa palestina como sendo sua, mobilizando-se politicamente contra a Síria durante a Guerra Civil Libanesa e tratando os poucos palestinos no Iraque com distinção positiva. Isso, por sua vez, reforçou a palestinidade e arabicidade (como complementares) sobre religião, especialmente dado que muitas das forças, opondo-se a Hussein, mobilizavam uma retórica islâmica. Além disso, pertencimento social não foi nesse contexto articulada em torno de um campo de refugiados ou algum território simbólico palestino, mas a palestinidade, como iteração da arabicidade, se manteve como um elemento central para a maioria dos sujeitos compondo o grupo.

Entretanto, como vimos, nem todos os palestinos dispersos pelo mundo são refugiados ou exilados e o caso latino-americano aqui é emblemático por se caracterizar por uma dispersão pré-exílio. A força e o apelo do espaço 
subjuntivo de palestinidade, sobretudo quando amparados por instituições como partidos, movimentos sociais, mas também clubes culturais e esportivos, leva palestinos no mundo todo a compartilhar uma noção de palestinidade romantizadamente ligada à temática do refúgio e do exílio. No entanto, na prática, a experiência da palestinidade varia enormemente de acordo com contexto e sujeito.

Desde 2015, entretanto, venho também pesquisando processos de pertencimento social entre refugiados árabes em geral, especialmente sírios e iraquianos na Áustria. O chamado "Verão da migração", quando refugiados particularmente de origem médio-oriental chegaram na Europa a partir do verão de 2015, pôs em evidência o encontro assimétrico entre a Europa e o Oriente Médio. Uma parte da população europeia, especialmente europeus de origem médio-oriental e parte da esquerda política, mobilizaram um jargão sociopolítico evocativo da história de suas relações internacionais com o Oriente Médio, ressignificando assim a história europeia e suas relações com a região para explicar aquilo que muitos entenderam como uma crise. Atores sociais evocaram esse encontro de formas diversas, empaticamente ou não, tornando esse jargão fortemente polissêmico. Assim, depois do verão de 2015, o conhecimento sobre as migrações médio-orientais na Europa tornou-se imperativo para compreender como tais sujeitos se engajam com a Europa, como conectam essa região ao Oriente Médio, e como esse encontro forma/é formado por processos sócio-históricos globais.

De fato, muitos projetos para pesquisa sobre refugiados médio-orientais na Europa emergiram depois do verão de 2015. Projetos sobre muçulmanos e árabes em geral também ganharam tração, motivados pelo impulso de sondar as "habilidades" dessas "comunidades" para se adaptar ou não à Europa. Dada a centralidade do contexto europeu e a ansiedade gerada pela chegada de um grande número de requerentes de asilo que, em sua maioria, eram de origem muçulmana, a maior parte desses projetos tem enfocado no que agentes estatais, assistentes sociais e acadêmicos chamam de "integração". Grande parte desses projetos, entretanto, resultou em visões distorcidas, as quais resultam de noções pré-concebidas que guiam questões de pesquisa e entrevistas e que prosperam 
em certos campos de pesquisa, já que o foco em integração tem origem em questões levantadas pelo senso comum, pela mídia e por governos, motivadas seja por medo ou por uma genuína preocupação com o futuro de médio-orientais, muçulmanos e refugiados.

A questão de refugiados médio-orientais na Europa não deve ser enquadrada primariamente como uma questão de religião, especialmente aquelas envolvendo a necessidade de se "domesticar" o islã e os muçulmanos, de forma que estes se adaptem, ou, como dizem, "se integrem" na Europa. Dito de outra forma, as pesquisas sobre refugiados não devem servir ao estabelecimento de uma lacuna religiosa incomensurável a priori, que precisa de uma "ponte" a qual, em verdade, apenas muçulmanos devem cruzar para chegar ao lado europeu.

Assim, minha proposta tem sido que evitemos os perigos da perspectiva da "integração" e as armadilhas da pesquisa não especializada nas ciências sociais em geral, e especialmente em antropologia, e que façamos isso mudando nossa perspectiva de análise, para evitar a predeterminação dos nossos resultados de pesquisa ao enquadrar o encontro entre o Oriente Médio e a Europa através da lente do estado-nação, da governança, da política, da segurança pública, ou ainda da assistência e da solidariedade. Tenho sugerido que é possível aglutinar muitas outras questões de pesquisa que apresentarei a seguir, e evitar a maior parte, senão todas, as armadilhas da pesquisa sobre integração, em uma única perspectiva de pesquisa que eu chamo simplesmente de "perspectiva do encontro", para evitar cunhar desnecessariamente mais um termo.

O encontro, nesse caso, entre médio-orientais (refugiados ou não) e o contexto europeu, não apaga a história dos sujeitos ou suas conexões empíricas e simbólicas entre a Europa e o Oriente Médio, tampouco restringe questões de pesquisa ao responder se médio-orientais podem se tornar culturalmente europeus, ou viver em um estado de direito nessa região. Em vez disso, a perspectiva do encontro busca criar amplos entendimentos de representações, interações, organizações, cosmologias e práticas sociais tais como estas existem realmente, diferentemente de noções preconcebidas que geram pontos-cegos sobre a estrutura mais ampla do encontro. Para usar uma metáfora médica, essa

3 Vide Schiocchet (2017b, 2018, in press 2019). 
perspectiva seria equivalente a produzir um diagnóstico geral antes de definir os termos de uma intervenção. Assim, essa concepção possui grande potencial para contribuir com o estudo de migrações médio-orientais (em oposição a estudos de comunidade, por exemplo), para a antropologia da (i)mobilidade, e para a conexão entre antropologia da migração e da migração forçada, já que esta gera um panorama compreensivo mas matizado da situação social analisada, necessário para a compreensão de questões antropológicas profundas sobre a natureza de interações sociais, identidade, pertencimento social, entre outras.

\section{PESQUISA, PERSPECTIVA E O CONTEXTO INSTITUCIONAL}

Hoje entendo que não é mera coincidência que minha produção acadêmica, ilustrada na primeira parte deste ensaio, recapitule minha própria situação pessoal, entre um país e outro, entre diferentes saberes e normatividades institucionais, como penso que ficará evidente nesta segunda parte.

Para minha graduação em Ciências Sociais na Universidade Federal do Paraná (UFPR) (2003), estudei relações de troca em comunidades caiçaras no litoral do Paraná. Para meu mestrado em Antropologia Social (Universidade de Brasília - UnB, 2005), estudei o conflito socioambiental envolvendo diferentes tradições de conhecimento entre pescadores caiçaras e uma aldeia indígena Guarani Mbyá na Ilha do Superagui - também no litoral do Paraná - bem como diversas agências do estado brasileiro e vários grupos ambientalistas.

Em minha ingenuidade então (possivelmente maior do que entre a maioria dos estudantes de graduação no Brasil hoje), julguei que para fazer o doutorado bastaria abrir um mapa, escolher um canto distante do mundo e encontrar uma forma de chegar até lá. Tinha ouvido histórias de como era possível atravessar o mundo cortando batatas ou limpando um convés de um navio de carga em troca da viagem necessária. Uma vez em meu destino, tentaria encontrar um trabalho qualquer, como lavar pratos em um restaurante de periferia, viver "como os nativos", aprender a língua, depois de alguns anos 
escrever uma monografia sobre minha experiência et voilá!, inevitavelmente minha rica experiência, expressa "em meu livro", me garantiria uma posição de professor em uma universidade brasileira, entendida como o fim de toda a epopeia acadêmica.

Enquanto cursava o mestrado na UnB, busquei o conselho de professores $^{4}$ e colegas para aprender como seria possível realizar esse objetivo e logo entendi que fazer antropologia exigiria muito mais do que isso. Exigiria inelutavelmente estar inserido em um contexto acadêmico. E, para tanto, precisaria seguir certas normas e provar excelência para "ser selecionado" e adquirir o capital financeiro e acadêmico necessários para, preferencialmente, me dedicar exclusivamente à pesquisa, que, portanto, não estava reduzida simplesmente à minha imersão no campo, mesmo após ter adquirido o que julgava ser então as ferramentas de pesquisa necessárias através da minha graduação e mestrado.

Meu primeiro projeto de pesquisa sobre Árabes e o Oriente Médio foi realizado no contexto do meu doutorado em antropologia pela Boston University (2005-2011). Como ocorre entre vários antropólogos, minha motivação em estudar o Oriente Médio foi advinda sobretudo de um anseio de entrar em contato com um outro, fetichizado como radicalmente diferente de mim. Esse anseio estava marcado então por uma vontade de estar imerso em uma realidade social com outras normas e costumes sociais, língua etc. Em perspectiva, hoje entendo que esse anseio sobretudo se ancorava em alicerçar uma posição que me propiciaria uma crítica social do mundo tal como eu o conhecia, inserido, entre outros, no contexto capitalista, brasileiro, moderno, ocidental e urbano. Vale apontar que essa realização em si não deve ser menosprezada, constituindo grande parte do processo de amadurecimento do meu fazer antropológico.

Meu doutorado na Boston University só foi possível através de uma bolsa da Capes/Fulbright existente então no contexto brasileiro. Ao contrário do que ocorre com a maioria dos países, a Fulbright, uma agência de fomento de pesquisa norte-americana autônoma, mas ligada ao Departamento de Estado, operou no Brasil em parceria com a Capes. Isso propiciou o financiamento de

\footnotetext{
Minha profunda gratidão aqui a Mariza Peirano e Paulo Gabriel Hilu Pinto por terem me guiado inicialmente, redimensionando minhas expectativas sem obstruir meus anseios.
} 
estudantes brasileiros no exterior por um período mais prolongado do que o que ocorre até hoje com outros programas da Fulbright. De acordo com esse compromisso, enquanto a Fulbright financiou minhas anuidades e taxas universitárias (caríssimas nos Estados Unidos (EUA), em relação a virtualmente qualquer outro contexto acadêmico no mundo) por quatro anos, a Capes garantiu recursos para que eu pudesse viver no país durante esse período. Tal acordo previa quatro anos de doutorado, segundo a expectativa brasileira, enquanto a expectativa em várias instituições de ensino em antropologia norte-americanas é de que o estudante permaneça em formação por pelo menos um ou dois anos mais, não sendo tão incomum que a formação leve seis ou sete anos. Assim sendo, ao cabo de meus quatro anos iniciais, o departamento de antropologia da Boston University sugeriu que eu deveria permanecer desenvolvendo minha tese por pelo menos mais um ano. Já sem a bolsa da Capes/ Fulbright, aceitei a premissa que eu deveria fazer como o resto de meus colegas e buscar outros financiamentos para terminar de escrever minha tese. Assim, escrevi um projeto de pesquisa para obter uma writing grant gerenciada pelo departamento de antropologia da Harvard University, chamada Cora DuBois, em homenagem à homônima antropóloga norte-americana. E depois dessa, escrevi outra proposta de wrting grant para uma instituição de pesquisa localizada em Viena, na Áustria, chamada IWM (Instituto para as Humanidades). Cada uma dessas bolsas teve duração de seis meses e, juntas, me garantiram mais um ano de escrita antes da defesa da minha tese.

Logo após a defesa do meu doutorado, voltei ao Brasil, o que mais uma vez só foi possível por conta de uma bolsa de pesquisa do governo brasileiro (pós-doutorado Júnior, CNPq, 2011-2013)5. Dessa vez, minha base institucional foi o departamento de antropologia da UFF, através do Núcleo de Estudos sobre o Oriente Médio (Neom), com o qual tinha mantido relações desde mesmo antes da minha partida do Brasil. Como o campo de estudos em

\footnotetext{
Ainda que minha defesa de doutorado tivesse ocorrido em maio de 2010, em muitas universidades nos Estados Unidos, para os que não podem participar presencialmente da cerimônia de graduação (commencement ceremony), os diplomas são apenas oficialmente distribuídos uma vez ao ano e, como minha defesa aconteceu dias após essa data, apenas obtive meu diploma oficial em 2011. No entanto, o $\mathrm{CNPq}$ aceitou um documento oficial de conclusão do doutorado, produzido pela Boston University.
} 
antropologia nos EUA tende a ser dominado por estudos de área, ao contrário da minha sólida formação teórica no Brasil, meu foco de estudos e as relações acadêmicas que estabeleci a partir desse momento foram fortemente marcadas por uma ênfase nos estudos sobre Oriente Médio, islã, e particularmente estudos palestinos e do Oriente Próximo. Dada a vasta literatura sobre esses assuntos em inglês, publicados em geral em revistas acadêmicas especializadas no tema, tive de início, um pouco a contragosto, de me adaptar a esse novo público. Vale apontar que essa tendência é talvez ainda mais forte no campo de estudos sobre o Oriente Médio e islã do que em outras áreas.

A volta ao Brasil, portanto, não foi fácil, sendo que eu tinha deixado o Brasil através de uma bolsa de pesquisa que enfatizava justamente explorar novas áreas de pesquisa no país, mas, quando voltei, encontrei pouquíssimos interlocutores (alguns resistentes à minha perspectiva e presença) para além do pequeno núcleo do Neom. Para que se tenha uma ideia, antes de mim, apenas um outro doutor e antropólogo brasileiro tinha realizado pesquisa etnográfica prolongada no Oriente Médio (Paulo Gabriel Hilu Pinto), enquanto uma de suas alunas (Gisele Chagas) tinha realizado pesquisa na região, mas ainda não tinha defendido seu doutorado. Ambos os pesquisadores compunham o pequeno grupo do Neom. Tentando fortalecer os estudos sobre Oriente Médio no Brasil, que, afinal, era o compromisso inicial de minha bolsa de doutorado pleno nos EUA, minha participação em congressos e produção acadêmica em português se voltaram para esse nicho, o que não ajudou minha inserção institucional. Muitos dos departamentos de antropologia estavam comprometidos com o desenvolvimento de áreas específicas de estudo e, por mais que tenha me esforçado em tentar criar pontes acadêmicas através dos temas teóricos que explorei em minha tese, como por exemplo, estudos sobre migração forçada e rituais, meu foco no Oriente Médio, com densas discussões terminológicas e específicas da região, não pareceu particularmente atrativa no contexto brasileiro para além do grupo do Neom e seus interlocutores. Ou ao menos essa foi minha impressão até então. Enquanto pesquisava o processo de reassentamento de um grupo de palestinos no Brasil advindos do conflito no Iraque tema que estava sendo concomitantemente explorado por pelo menos duas 
doutorandas brasileiras (Sônia Hamid e Daniele Abilas Prates), minha discussão se voltava aos temas de pesquisa e a literatura com a qual tinha me familiarizado fora do país, em diálogo com minha pesquisa de doutorado. Durante os dois anos em que realizei minha primeira pesquisa de pós-doutorado, participei de concursos para professor em antropologia em alguns departamentos de universidades federais (aqueles que estavam disponíveis no momento ${ }^{6}$ ). Para além disso, o processo de validação do meu diploma de doutorado (pela UFF) tomou grande parte de meus esforços.

Minha vida pessoal seguia em paralelo. Durante os cinco anos que estive fora do Brasil, conheci e me casei com uma americana nascida no Líbano de pai palestino, que deixou sua família, o país em que cresceu (EUA), seu emprego e suas relações sociais estabelecidas, para me acompanhar de volta ao Brasil. Entre o Rio de Janeiro, minha base acadêmica, Curitiba, onde minha esposa dava aulas de yoga que mal pagavam seu transporte público, e minhas frequentes viagens para o interior do Brasil (sobretudo a Amazônia), onde realizava consultoria em educação, esse período foi também marcado por forte instabilidade afetiva. $\mathrm{O}$ fato de que alguns dos concursos públicos que participei exigiam diálogo com uma bibliografia específica, enquanto outros se voltavam para sorteio de temas, a maioria deles periféricos para meu próprio projeto de pesquisa mais amplo, ampliou a sensação de instabilidade. Nesses dois anos, não obtive sucesso, mesmo em posições de pós-doutorado com seleção simples ou como professor substituto que se enquadravam em minhas próprias linhas de pesquisa, como por exemplo, "rituais e simbolismo".

Assim sendo, fiz o que sabia fazer de melhor: escrevi um outro projeto de pós-doutorado, alicerçado em minha experiência de pesquisa no exterior e meus contatos fora do Brasil. Foi assim que iniciei minha pesquisa entre palestinos na Dinamarca, através de uma bolsa de doutorado sênior no exterior da Capes (2013-2014). Para além dos seis meses de pesquisa de campo na Dinamarca, esse projeto também previu um ano de escrita na minha instituição europeia anfitriã, o Instituto para Antropologia Social (ISA) da Academia Austríaca de

Assim, não pude, é claro, escolher um departamento com o qual já possuía um diálogo, como o da UFF, ou ainda um com o qual poderia desenvolver um diálogo mais próximo. 
Ciências (ÖAW), em Viena, marcando meu segundo período de intercâmbio acadêmico nessa cidade. Ao final desse período, voltei ao Brasil, mas continuei desenvolvendo pesquisa através do ISA. Tanto por receio de não encontrar uma posição no Brasil - o que se tornou de fato realidade - quanto pela fluidez do meu diálogo antropológico nessa instituição e no contexto europeu ${ }^{7}$, que possuía o Oriente Médio e o islã como dois de seus tópicos centrais, continuei, como sempre, publicando tanto em português quanto em inglês. Durante essa fase, mais uma vez estive inserido academicamente no Programa de Pós-Graduação em Antropologia (PPGA) da UFF, através de mais um pós-doutorado que incluía pesquisa entre palestinos na Áustria, bem como, mais uma vez - tal como durante meu primeiro período de pós-doutorado no PPGA-UFF -, o ensino de disciplinas voltadas à antropologia do Oriente Médio e a antropologia da migração forçada.

No verão de 2015 então, quando um grande número de refugiados, sobretudo advindos do Oriente Médio, chegou à Europa, muitos deles passando desde os Balcãs pela Áustria em direção à Alemanha, Holanda ou Suécia, fui convidado a ser o principal investigador de um projeto de estudo sobre o tema desde o ISA. Sem um emprego no Brasil, voltei então à Viena, mais uma vez em companhia de minha esposa, para ainda mais um período de pós-doutorado (2015-2017), dessa vez financiado pelo Fundo Científico Austríaco (FWF). Desde o ISA, tomei a iniciativa de sugerir e ajudar a organizar duas mesas-redondas convocando os especialistas sobre migração e migração forçada das principais instituições de pesquisa austríacas. Haja visto o sucesso dessas duas mesas, com a participação de mais de uma dúzia de pesquisadores, encontrei espaço para fundar, junto a outras duas acadêmicas do próprio ISA, a Refugee Outreach \& Research Network (ROR-n), que hoje possui mais de duas dezenas de parceiros na Áustria e no exterior, incluindo a Inglaterra, Líbano e Alemanha. Durante os primeiros anos da ROR-n, fiz parte da comissão executiva dessa rede, junto a outra colega do ISA (Maria Six-Hohenbalken) e editor do blog desta, junto a outra colega da ÖAW (Monika Mokre). Com a intenção de manter a pluralidade institucional e de me dedicar mais exclusivamente à

Ainda mais do que o Americano, dada a questão política envolvida em estudos palestinos. 
pesquisa, renunciei à minha posição na comissão executiva da rede em dezembro de 2018, mantendo minha posição de editor do blog. Concomitantemente, minha esposa encontrou trabalho em Viena e tivemos uma filha nessa cidade, o que contribuiu nossa sensação de estabilidade financeira e afetiva, para além de certa estabilidade institucional.

Ao fim desse projeto de pós-doutorado, minha posição na ROR-n me levou a participar de mais um projeto de pesquisa entre árabes refugiados em Viena, mais uma vez, entretanto, como pós-doutorando sênior, como colaborador. Esse projeto, financiado pelo Innovation Funds Programme da Academia Austríaca de Ciências através de ROR-n, durou um ano, e ao fim desse projeto, fui mais uma vez convidado pelo diretor do ISA, Andre Gingrich, a continuar meu trabalho acadêmico dessa instituição. Mais uma vez recebi financiamento da FWF, como investigador principal de um projeto de pesquisa que visa aprofundar meu primeiro trabalho com a instituição sobre o que chamo de o "encontro austro-palestino", mas expandindo o tema para incluir o "encontro austro-árabe” de forma geral. Recebi fundos para contratar uma pós-doutoranda (Sabina Bauer-Amin) e dois refugiados árabes como estudantes estagiários. Esse projeto se iniciou em 2018 e está previsto para terminar em 2022.

Durante esse novo período de pesquisa no ISA/ROR-n, tornei-me também editor assistente da revista acadêmica Anthropology of the Contemporary Middle East and Central Eurasia (ACME, Sean Kingston Publishing, UK), ligada à Associação Europeia de Antropologia (EASA) - uma das duas revistas acadêmicas no mundo especializadas na antropologia do Oriente Médio. Mantive minha posição nessa revista até março de 2019, quando passei a trabalhar na equipe editorial da Anthropology of the Middle East (AME, Berghanh), sendo esta a segunda revista em questão. A AME, por sua vez, é ligada à comissão de Antropologia do Oriente Médio da IUAES, da qual me tornei, em 2018, o representante europeu. 


\section{CONTEXTO E NORMATIVIDADE NO FAZER ACADÊMICO}

Entendo que minha trajetória acadêmica, tal como apresentada neste ensaio, certamente não pode ser generalizada. Entretanto, entendo que evidencia algumas questões estruturais importantes sobre o fazer acadêmico/antropológico dentro e fora do Brasil, sobre algumas das principais vantagens e desafios da formação - especialmente parcial - de brasileiros fora do país, e sobretudo sobre a relação entre contexto e normatividade acadêmica, disciplinar e institucional.

Ao ler sobretudo a primeira parte deste ensaio, talvez o leitor reconheça na minha produção acadêmica temas de pesquisa e perspectivas teóricas que ressoam com suas próprias. Talvez o leitor julgue mesmo que minha produção acadêmica é relevante o suficiente para me garantir boas chances de inclusão na academia brasileira. Talvez se pergunte afinal qual teria sido a minha dificuldade em promover minha pesquisa em relação a linhas de pesquisa e departamentos brasileiros. Ao ler a segunda parte deste artigo, talvez o leitor se pergunte sobre as raízes da minha crítica à normatividade institucional acadêmica (dentro e fora do Brasil), mesmo porque talvez a minha própria precariedade institucional não seja tão aparente. A resposta para essas perguntas, creio, está sobretudo inscrita em dinâmicas institucionais; depende ao menos no tanto de linhas de pesquisa desenvolvidas em um ou outro departamento, quanto de afinidade intelectual e pessoal e contexto situacional. Acima de tudo, acadêmicos em geral não podem simplesmente escolher suas bases institucionais, ou ao menos não em princípio, não ao menos sem ter antes suporte através de redes acadêmicas - o que por sua vez não depende apenas de afinidade intelectual e competência acadêmica.

Além disso, aprendemos a construir currículos baseados em sucessos, ocultando as pedras que encontramos no caminho. Também aprendemos a isolar nossa vida pessoal, segregando-a de nossas narrativas acadêmicas, muitas vezes tratando sua menção como tabu, sinal de fraqueza, ou de falta de seriedade acadêmica. Por fim, aprendemos a sentir-nos privilegiados frente àqueles que possuem ainda menos, e nos resignar a contentar com o que temos. Talvez 
a principal lição que aprendi em minha trajetória acadêmica, como evidenciado nas primeiras duas partes deste ensaio, é que todas estas questões fazem parte de um repertório comum que habita um espaço subjuntivo que coexiste em contextos específicos. Como defini na primeira parte deste ensaio, defino este espaço (tempo) subjuntivo como imaginado, compartilhado, idealizado e inerentemente polifônico e disputado, estruturado tanto por conceitos quanto por relações sociais, emoções e disposições, que se articula a cada iteração contextual, assim dinamicamente constantemente se ressignificando. Em outras palavras, o próprio campo acadêmico em si possui certa normatividade para além de questões relativas ao contexto. Essas ocultações, segregações e autoflagelo por sentimento de culpa estão inscritas na normatividade institucional acadêmica e influenciam diretamente na produção do acadêmico, tanto no Brasil quanto fora dele. O que varia é a posição relativa do sujeito no sistema, determinando sua escala de exposição a essas questões, e as diversas formas com que tais questões têm ou não sido compreendidas, absorvidas ou resistidas por sujeitos individuais e coletivos.

Por um lado, uma das questões que julgo mais evidente sobre o que apresentei até aqui é que minha trajetória acadêmica, e particularmente os vários estágios da minha pesquisa no exterior, não poderiam ter acontecido senão através do suporte institucional da academia brasileira e do contexto institucional da educação neste país. Em primeiro lugar, precisei da experiência de acadêmicos brasileiros tanto para me oferecer uma sólida educação antropológica, quanto para me guiar no processo de desenvolvimento acadêmico. Obtive ambos tanto desde a minha graduação na UFPR e meu mestrado na UnB, quanto através do apoio continuado de antropólogos situados no Brasil enquanto estive fora do país. Em segundo lugar, precisei do apoio institucional e financeiro providenciado por instituições tais como a Capes e o CNPq, sem os quais não teria sido possível realizar pesquisa de campo fora do Brasil, doutorado e pós-doutorado dentro e fora dele, ou mesmo minha graduação e mestrado no Brasil, para os quais também pude contar com bolsas de pesquisa brasileiras que asseguraram que eu pudesse me dedicar quase que exclusivamente à minha formação acadêmica de forma a adquirir o conhecimento acadêmico 
necessário para ser reconhecido como potencial aluno no exterior e para exercer minha profissão dentro e fora do Brasil. Impossível não reconhecer meus privilégios, tanto como parte da classe média que me permitiu sequer cogitar uma possível carreira acadêmica e nas ciências sociais, quanto como alguém que foi escolhido para receber as diversas bolsas de pesquisa que tenho recebido até aqui e assim desenvolver minha pesquisa e minha produção intelectual.

Por outro lado, o reconhecimento desse privilégio não deve ser entendido como justificativa para o ocultamento da estrutura acadêmica à qual está atrelada e não pode ser justificativa para resignação frente a estruturas ineficazes que reproduzem certas relações de poder e não contribuem para o desenvolvimento do campo. Além disso, todo esse suporte institucional brasileiro presente no meu caso, em si, não garante a possibilidade de uma trajetória satisfatória, a reinserção do cientista de volta ao Brasil, ou mesmo a segurança de que o investimento intelectual, institucional e financeiro no pesquisador traga retorno à academia brasileira. Em primeiro lugar, minha carreira não foi marcada apenas por vitórias, ainda que eu tenha primeiramente escolhido estas para marcar minha narrativa acadêmica. Foram muitas as dificuldades, quedas, bolsas e posições acadêmicas para as quais não fui eleito. Também foram muitas as dificuldades, quedas, bolsas e posições acadêmicas que presenciei de competentes colegas no Brasil e fora dele. Em verdade, não foram sobretudo as minhas, mas as deles, que me fizeram refletir sobre a realidade da chamada "meritocracia" acadêmica. Para cada posição que competi, havia outros acadêmicos ao menos tão competentes quanto eu que não foram contemplados, assim como julguei muitas das minhas rejeições arbitrárias. No entanto, uma após outra, tais decisões foram apresentadas como uma questão de mérito, como se houvesse critérios absolutamente objetivos para decidir qual "o melhor" antropólogo, a despeito de diferentes temas, perspectivas, e experiências de pesquisa. Em toda parte, os regimes de verdade (FAUBION, 2002) criados em torno da ideia de meritocracia se dão em grande medida como justificativa para autonomia, imparcialidade e irrevocabilidade de decisões que de fato dependem também de afinidade de interesses, temas e perspectivas de pesquisa, quando não diretamente de lobby e barganhas institucionais e da economia de 
capital simbólico (por exemplo, através do posicionamento pessoal do candidato e seu status em relação ao campo disciplinar de forma geral). Essa estrutura não está limitada apenas a seleções de bolsas ou de tenured positions, mas sua capilaridade se estende à aceitação/rejeição de artigos acadêmicos, propostas de painéis e trabalhos em conferências, convites para palestras e outros.

Somando-se a isso, princípios seletivos que exigem inscrição presencial, sorteio de temas, engajamento como bibliografia dada de antemão, ônus financeiro do concurso depositado no próprio candidato, e outras questões que entendo como muito mais presentes no contexto brasileiro do que em outros com os quais engajei na Europa, EUA e Oriente Médio, não capitalizam o conhecimento próprio do candidato, mas sim reproduzem homogeneidade, reforçam relações de poder de centros específicos de produção acadêmica e linhagens de antropólogos. Sobretudo, tais processos institucionais tendem a dificultar o acesso de intelectuais advindos de outras tradições acadêmicas, explorando novas áreas de pesquisa, e não estabelecidos em redes de contato relativas a cada uma das instituições de pesquisa, no Brasil ou fora dele, onde se apresenta como candidato. Vale reiterar que cada contexto acadêmico possui sua própria especificidade legitimada em relação ao espaço subjuntivo acadêmico global em si polifônico tal como apontei anteriormente - e que, portanto, os contextos norte-americano, europeus e médio-orientais com os quais me engajei possuem também certas limitações e vantagens. Não se trata aqui, por conseguinte, de hierarquizar tais contextos em termos de "melhores" ou "piores", mas sim de apontar algumas das limitações do contexto brasileiro tendo este último como comunidade de comunicação (HABERMAS, 1984). Em outras palavras, a crítica aqui presente visa apontar para possíveis áreas de desenvolvimento futuro em um contexto no qual estou inscrito.

No meu caso particular exposto aqui, tais relações efetivamente fizeram da minha inserção no Brasil bastante insular e limitada, me mobilizando a voltar vez após outra para fora do Brasil e para os contextos nos quais minha perspectiva analítica, meu tema de estudo e meu conhecimento estrutural e know-how seriam possivelmente mais adequados. Aliado a isso, por mais que tenha encontrado afinidade intelectual, estabelecido relações acadêmicas, e 
portas abertas no PPGA-UFF, o contexto institucional e minha vida pessoal não ecoaram em uníssono. Na única ocasião em que poderia ter prestado concurso nessa instituição, minha vida pessoal não me permitiu. O que nos leva a outro ponto importante: dada a natureza de contratações e oportunidade de trabalho, acadêmicos raramente podem escolher onde se estabelecer, mas perseguem oportunidades onde elas estiverem. Diferentemente de outras profissões, não podemos nos manter presentes em uma dada cidade ou, no meu caso, mesmo país, à espera de um contrato de trabalho. Ponderamos com as poucas cartas que temos em mãos, e escolhemos caminhos fortuitos. Além disso, nem sempre temos o privilégio de colocar nossas carreiras em primeiro plano. Por exemplo, aqueles que possuem familiares doentes, ou parceiros(as) e/ou filhos, não podem deixar suas vidas para trás para seguir seus anseios acadêmicos. Deve haver certo equilíbrio e flexibilidade que hoje não existe em virtualmente qualquer contexto institucional e talvez nunca tenha existido. Durante minha trajetória acadêmica, não foram poucos os competentes antropólogos que vi deixar o campo e mesmo a academia como um todo, não por vontade pessoal, mas por impossibilidade estrutural - impossibilidade esta, ligada tanto à normatividade acadêmica profundamente atrelada ao que chamei anteriormente de um espaço subjuntivo acadêmico, que existe para além de cada contexto, quanto ao contexto de cada uma de suas iterações - nesse caso, o contexto acadêmico brasileiro contemporâneo.

A vida não para. Nos adequamos a certas expectativas, contextos, interlocutores acadêmicos, e os imponderáveis da vida. Muitas vezes não é possível ou mesmo desejável deixar nossas vidas pessoais de lado para fechar um circuito moral, de certa forma ingênuo, necessariamente atrelado à "volta"; como se o retorno nos levasse de volta ao passado; como se o mundo não tivesse girado enquanto estivemos fora; como se a única forma de retorno fosse física. Em meu trabalho etnográfico, aprendi que, diante da impossibilidade de retorno físico a uma Palestina originária, palestinos habitam a Palestina (e a Palestinidade) como um destino moral (MALKKI, 1992, 1995a, 1995b). Da mesma forma, também não devemos pensar no retorno de acadêmicos brasileiros no exterior como uma obrigação de retorno a um território geográfico. 
Com meu retorno ao Brasil, aprendi que a ida e a volta são igualmente necessárias para o estabelecimento de redes de produção e circulação de conhecimento, como espero que este artigo tenha mostrado. Minha volta ao Brasil, entretanto, não se deu apenas durante os quatro anos que passei fisicamente presente neste país, mas aos semestres que ritualmente ainda passo, desde minha estadia agora oficial no exterior, ensinando na UFF ou realizando pesquisa de campo no Brasil. Meu retorno é moral, se dá a cada artigo, capítulo ou livro que produzo em português, tal como este. Meu retorno se dá a cada porta que abro para alunos brasileiros no exterior através de produção intelectual em revistas acadêmicas nas quais estou envolvido, a cada palestrante brasileiro que ajudo a levar ao exterior, a cada participação minha em eventos acadêmicos brasileiros, a cada evento que realizo no Brasil trazendo intelectuais de fora do país, e a cada lembrança de um intelectual brasileiro que marca meu fazer antropológico. Para cada grupo de acadêmicos que voltam ao Brasil após estágios no exterior, entendo que seja necessária a manutenção de outros no polo oposto do circuito de produção intelectual. Em verdade, entendo que meu atual período fora do Brasil é aquele no qual tenho podido contribuir de forma mais incisiva para o desenvolvimento da antropologia do Oriente Médio e da migração forçada no Brasil. Entretanto, isso só é possível devido ao retorno de outros antropólogos brasileiros, particularmente à UFF, com os quais mantenho fortes laços acadêmicos. Dito em outras palavras, tanto o contexto institucional acadêmico no Brasil, quanto acadêmicos que visam períodos de formação no exterior, não devem esperar necessariamente um retorno geográfico ao Brasil como forma necessária de fechamento de um ciclo no exterior. Muitas vezes isso não é desejável, muitas vezes isso não é sequer possível.

Entretanto, como meu próprio caso demonstra, a despeito do espaço subjuntivo acadêmico global, compartilhado, negociado, resistido e ressignificado a cada contexto, a inserção de pesquisadores advindos de contextos distintos também traz suas dificuldades. Para o antropólogo brasileiro (e outros) no exterior, a normatividade acadêmica se faz presente sobretudo através da hegemonia de certos contextos específicos e, em particular, da hegemonia anglófona, dominada por fazeres acadêmicos advindos sobretudo dos EUA e Reino 
Unido. Essa questão se torna especialmente importante dado que os brasileiros têm o brilhantemente chamado de "complexo de vira-latas" - quer dizer, a suposição de que tudo que vem do exterior é melhor do que é produzido no Brasil. Surpreendentemente, o imaginário de que o antropólogo no exterior está necessariamente mais bem localizado do que no Brasil está ainda muito presente na academia brasileira. Não retornar (no sentido geográfico) é assim entendido como sinal de "sucesso". Mas a situação é muito mais complexa.

Uma das primeiras lições que aprendi no exterior é que a produção em português é praticamente ignorada. Isso, é claro, não acontece da mesma forma no caso de contextos de pesquisa americanistas, nas quais o português e a experiência de pesquisa no Brasil são altamente valorizados. Isso também não ocorre com a mesma intensidade em certos estágios de carreira e, portanto, atinge muito menos antropólogos brasileiros com carreiras bem estabelecidas no Brasil. Entretanto, a hegemonia do fazer antropológico anglófono (em si, também relativamente plural) afeta especialmente doutores brasileiros que visam se estabelecer fora do país. Justamente por sua forte resistência à hegemonia do contexto anglófono, o contexto francês tem, tradicionalmente, sido menos resistente a brasileiros nesse estágio de suas carreiras. Entretanto, obter uma posição institucional permanente nesse país, para não americanistas, é talvez tão ou mais difícil quanto fazê-lo nos EUA ou em outros contextos europeus.

Além do mais, a hegemonia anglófona não se dá apenas diretamente pelo domínio da produção antropológica em grandes centros de pesquisa norte-americanos e britânicos, mas sobretudo através de ideologia linguística (SILVERSTEIN, 1985) ou ideologia semiótica (KEANE, 2007). Através de ideologia linguística, a hegemonia anglófona se faz presente sobretudo através da importância da produção acadêmica em inglês, tida como absolutamente fundamental em contextos antropológicos anglófonos. "Escrever em inglês", assim, não se limita simplesmente à tradução de artigos, capítulos e livros diretamente do português para o inglês, ou mesmo em escrever, tal como se faria em português, em inglês. Escrever em inglês envolve o aprendizado de técnicas específicas que envolvem o domínio de formatos específicos, de certa forma de escrever. Tais formas, por sua vez, por vezes diferem radicalmente de 
outras praticadas, por exemplo, na França ou no Brasil e, portanto, dependem da capacidade do autor em emular da literatura anglófona em si. Ainda que centros de pesquisa em antropologia no mundo produzam em inglês, muito dessa literatura é ignorada, seja por não se adequar às normas, seja por métricas de produção acadêmicas que tomam como base o contexto acadêmico anglófono em detrimento de outras. Tais métricas de produções intelectuais incluem principalmente a publicação de artigos acadêmicos avaliados por pares e indexados segundo índices específicos, tal como no caso brasileiro. Também como no caso brasileiro, essa indexação é, em parte, arbitrária. Por exemplo, se um autor publicou um artigo em uma das mais importantes revistas acadêmicas da área de estudos médio-orientais, e tal revista não está indexada em um dos índices escolhidos como padrão, esse artigo pouco ou nada conta como métrica de produção acadêmica de tal autor, influenciando decisivamente na distribuição de recursos como financiamentos de pesquisa ou posições institucionais. Isso pesa drasticamente na produção acadêmica, determinando, por exemplo, a forma de publicação científica, quem deve ser considerado como interlocutor e, assim, não apenas como o autor deve produzir, mas também com quem deve dialogar e como deve recortar seu objeto de estudo.

Além disso, o fazer antropológico no contexto anglófono, dominante na maior parte do mundo, como na Áustria, Holanda e Alemanha, e inclusive no sul global, como no Oriente Médio, exige a elaboração de um currículo em certos moldes que incluem não apenas a produção acadêmica em certas revistas em detrimento de outras, mas também a obtenção de financiamento de pesquisa externo (third part funding) preferencialmente de certas agências em detrimento de outras. No meu caso, a hegemonia do contexto anglófono, aliado ao meu constante retorno ao Brasil enquanto destino moral, tem exigido esforços muitas vezes opostos, fazendo do meu engajamento intelectual algo quase esquizofrênico. Mesmo tendo publicado nos lugares "certos" e obtido financiamento de algumas das agências de financiamento "desejáveis", sigo sem um emprego fixo e caminho definido, mesmo após inúmeros pós-doutorados. Teria certamente preferido uma posição permanente no Brasil. 


\section{CONCLUSÃO}

O testemunho explicitado no trajeto acadêmico presente aqui não deve ser interpretado segundo métricas de avaliação científicas. Meu esforço até aqui tem sido outro: ilustrar a estrutura do campo acadêmico e, em especial, antropológico, em termos da relação entre contextos institucionais distintos e a normatividade do campo. O exemplo empírico desenvolvido aqui não se limita também a pesquisadores na mesma etapa de carreira que a minha. Constantemente recebo pedidos de conselho de antropólogos brasileiros sobre como conduzir suas próprias carreiras em vistas ao exterior, ou simplesmente buscando adquirir informação sobre a antropologia fora do Brasil. Este ensaio visou contribuir para esse esforço, eventualmente ajudando a informar e/ou preparar acadêmicos brasileiros para estágios de pesquisa no exterior, oferecendo conhecimento de base para ajustar currículos e expectativas para outros contextos para além do brasileiro. O objetivo central deste ensaio, entretanto, é de servir como base para discussões sobre o campo institucional da pesquisa antropológica no Brasil em perspectiva comparada e da normatividade do campo acadêmico em escala global.

Para além de bibliografia temática específica, dentre os conselhos mais requisitados a mim estão para onde enviar artigos acadêmicos para serem publicados no exterior e como adquirir financiamento de pesquisa fora do Brasil. A resposta é sempre relativa não apenas ao contexto, mas também à expectativa do acadêmico. Se ele busca apenas diálogo no exterior, a necessidade de produção acadêmica em inglês e em revistas acadêmicas específicas se reduz, pois o diálogo acadêmico não precisa passar necessariamente por centros hegemônicos. Contatos entre acadêmicos brasileiros com outros médio-orientais, poloneses, japoneses, tailandeses e outros geralmente dependem do domínio do inglês e de certa produção em inglês para que possa haver diálogo profundo. Em outras partes do mundo, como o mundo pós-colonial português, a América Latina e parte da África, o antropólogo brasileiro pode usar o português, espanhol e francês como língua franca. Entretanto, o inglês, e com ele o campo institucional anglófono, tem cada vez mais se reproduzido 
como dominante. Nesse sentido, gostaria de deixar aqui uma reflexão importante baseada no que aprendi entre refugiados árabes:

Por mais que eu fale árabe coloquial do Oriente Próximo, vários dos meus interlocutores em campo preferiram o inglês como língua ao menos parcial de comunicação, ou uma mistura de árabe e inglês. Isso se deu mesmo em campos de refugiados palestinos no Líbano, onde a grande maioria dos meus interlocutores conhecia muito pouco ou nada de inglês. Em verdade, em um dos campos de refugiados nos quais residi, o xeique da mesquita me pediu que eu oferecesse aulas de inglês para as crianças do campo. Da mesma forma, uma ONG palestina na qual trabalhei como voluntário também me pediu o mesmo. Assim, tive muitos alunos no campo, para além daqueles que simplesmente tentavam seu melhor para se comunicar comigo em inglês, a despeito da minha insistência um pouco ingênua no árabe como única "língua de pesquisa de campo". Enquanto havia algo de status nas motivações de alguns, todos justificavam seus esforços ao menos em parte em termos da necessidade de se comunicar com não árabes, sobretudo de forma a comunicar suas experiências e perspectivas sobre a questão palestina, islã, e assuntos mais mundanos. Para uma resistência eficaz, enfim, necessita-se da palavra.

Por fim, para além da minha continuada instabilidade institucional, vale lembrar mais uma vez dos meus privilégios, reiterando que, por mais modesta que seja, minha carreira até aqui só foi possível por conta da minha sólida formação antropológica no Brasil, do continuado suporte de intelectuais brasileiros e do contexto institucional acadêmico privilegiado no país de mais de uma década que se seguiu a partir de 2003 - quando iniciei o processo de seleção da minha bolsa de doutorado pleno no exterior (Capes/Fulbright).

Infelizmente, o presente contexto institucional acadêmico brasileiro, a partir de 2019, tem sido marcado pelo desmonte do ensino público e sobretudo da pesquisa científica. A falta de financiamento não atinge somente aqueles que buscam formação no exterior, mas mesmo aqueles que buscam formação plena no território nacional. Se, por um lado, financiamento para pesquisa no exterior está entre as primeiras áreas atingidas, por outro, a demanda chegada a mim por conhecimento sobre espaço institucional acadêmico no exterior 
tem aumentado. Isso se deve claramente à forte percepção de falta de oportunidade no Brasil. Para aqueles que buscam se aventurar fora, por vontade ou necessidade, adaptação a outros contextos acadêmicos se tornou ainda mais essencial. Tão importante quanto isso, entretanto, é o conhecimento da relação entre contexto e espaço, inerentemente polifônico, da antropologia enquanto disciplina acadêmica. Como no caso dos meus interlocutores palestinos e outros árabes refugiados, insisto que esse conhecimento é fundamental, mesmo que apenas para que aprendamos a nos posicionar perante esse campo e resistir a suas hegemonias.

\section{REFERÊNCIAS}

1. FAUBION, James D. (ed.). Power: the essential works of Michel Foucault 1954-1984. London: Penguin, 2002. v. 3.

2. HABERMAS, Jürgen. Theory of communicative action: reason and the rationalization of society. Boston: Beacon Press, 1984. v. 1.

3. KEANE, Webb. Christian moderns: freedom and fetish in the mission encounter. Berkeley: University of California Press, 2007.

4. LATOUR, Bruno. We have never been modern. Cambridge: Harvard University Press, 1993.

5. MALKKI, Liisa. National geographic: the rooting of peoples and the territorialization of national identity among scholars and refugees. Cultural Anthropology, Arlington, v. 7, n. 1, p. 24-44, 1992.

6. MALKKI, Liisa. Purity and exile: violence, memory, and national cosmology among Hutu refugees in Tanzania. Chicago: University of Chicago Press, 1995a.

7. MALKKI, Liisa. Refugees and exile: from "refugee studies" to the national order of things. Annual Review of Anthropology, Palo Alto, v. 24, p. 495-523, 1995b.

8. PALESTINIAN CENTRAL BUREAU OF STATISTICS. Estimated number of Palestinians in the world by country of residence, end year 2015. [S. l.]: PCBS, 2015. Disponível em: http://bit.ly/2JjnsYb. Acesso em: 9 set. 2018.

9. ROY, Olivier. The Islamization of radicalism. Rosa Luxemburg Stiftung: North Africa Office, 2016. 
10. ROY, Olivier. Globalized Islam: the search for a new Ummah. New York: Columbia University Press, 2004.

11. SCHIOCCHET, Leonardo. O encontro euro-médio oriental: uma proposta de programa de pesquisa. Novos Debates, Brasília, DF, v. 4, n. 1, [2019?]. No prelo.

12. SCHIOCCHET, Leonardo. Outcasts among Undesirables: 117 Palestinian Refugees in Brazil in-between Humanitarianism and Nationalism. Latin American Perspectives, [S. l.], v. 46, n. 3, p. 84-101, 2019. doi: 10.1177/0094582X19831683.

13. SCHIOCCHET, Leonardo. Anthropologists and refugees between global hegemony and the subaltern 'other'. Anthropology of the Contemporary Middle East and Central Eurasia, Herefordshire, v. 4, n. 2, p.1-10, 2018.

14. SCHIOCCHET, Leonardo. Integration and encounter in humanitarian tutelage. In: KOLBACHER, Josef; SCHIOCCHET, Leonardo (ed.). From destination to integration: Afghan, Syrian And Iraqi Refugees in Vienna. Vienna: Austrian Academy of Sciences Press, 2017. p. 9-35.

15. SCHIOCCHET, Leonardo. Palestinian steadfastness as a mission. In HORSTMANN, Alexander; JUNG, Jin-Heon (ed.) Building Noah's ark for migrants, refugees, and religious communities. New York: Palgrave MacMillan, 2015.p. 209-234.

16. SCHIOCCHET, Leonardo. Palestinian Sumud: steadfastness, ritual and time among Palestinian refugees. In: KHALIL, Asem (ed.). Palestinian refugees: different generations but one identity. Ramalllah: Ibrahim Abu-Lughod Institute of International Studies, 2013. p. 67-90.

17. SILVERSTEIN, Michael. Language and the culture of gender: at the intersection of structure, usage and ideology. Orlando: Academic Press, 1985. p. 219-259.. 